\title{
Influence of Saltwater Submergence on Geohydraulic Properties of Sand: A Laboratory Investigation
}

\author{
Sudip Basack ${ }^{1, *(D)}$, Ghritartha Goswami ${ }^{2}$, Sumanpran Sonowal ${ }^{3}$ and Moses Karakouzian $4, *$ (D) \\ 1 Elitte College of Engineering, Affiliated: MAKA University of Technology, Kolkata 700113, India \\ 2 Civil Engineering Department, North Eastern Regional Institute of Science and Technology, Nirjuli 791109, India; \\ er.ghritartha@gmail.com \\ 3 Water Resources Department, Government of Assam, Guwahati 781029, India; suman.sonowal@gmail.com \\ 4 Civil Engineering, International Recycled Rubber Product Initiative, University of Nevada, \\ Las Vegas, NV 89154, USA \\ * Correspondence: basackdrs@hotmail.com (S.B.); mkar@unlv.nevada.edu (M.K.); \\ Tel.: +91-8617715761 (S.B.); +1-7026827096 (M.K.)
}

Citation: Basack, S.; Goswami, G.;

Sonowal, S.; Karakouzian, M.

Influence of Saltwater Submergence on Geohydraulic Properties of Sand A Laboratory Investigation.

Hydrology 2021, 8, 181. https:// doi.org/10.3390/hydrology8040181

Academic Editor: Roohollah Noori

Received: 17 November 2021

Accepted: 7 December 2021

Published: 8 December 2021

Publisher's Note: MDPI stays neutral with regard to jurisdictional claims in published maps and institutional affiliations.

Copyright: (c) 2021 by the authors. Licensee MDPI, Basel, Switzerland. This article is an open access article distributed under the terms and conditions of the Creative Commons Attribution (CC BY) license (https:// creativecommons.org/licenses/by/ $4.0 /)$.

\begin{abstract}
Saline water intrusion into freshwater aquifers is a major geohydraulic problem relevant to coastal environment. Apart from contaminating the fresh groundwater resources, the saltwater intrusion alters the geotechnical properties of the aquifer materials, affecting the coastal water resource planning and management. The present study focuses on an in-depth laboratory investigation of the influence of saltwater submergence on the geohydraulic properties of sand. The fine sand sample was submerged under saline water of specified concentrations for specific periods, and the alteration in their engineering properties has been studied. It is observed that the specific gravity, dry density, and permeability of fine sand is significantly affected by the period of submergence and saline concentration. The specific gravity of sand particles was observed to increase almost linearly with period of submergence and saline concentration. While the sand dry density decreased fairly linearly with the period of submergence, the same is not being affected significantly by saline concentration. The permeability of sand increased nonlinearly with both period of submergence and saline concentration; for a submergence period of 14 days and saline concentration of 30,000 ppm, the permeability increased to a maximum value.
\end{abstract}

Keywords: aquifer; dry density; permeability; saline water intrusion; sand; specific gravity

\section{Introduction}

The term salinity may be defined as the total concentration of all soluble salts in the soil. Saline soils basically consist of chlorides, sulphates and carbonates of sodium, calcium and magnesium, with the most common salt being sodium chloride [1].

The increasing demand of freshwater extraction in coastal regions initiates the saltwater's interface to advance towards the aquifers, producing saline water intrusion [2]. Such intrusion not only contaminates the fresh groundwater making it significantly unsuitable for human, irrigation, and industry usages, but also alters the geotechnical and geohydraulic properties of the aquifer materials, affecting the pumping and other engineering activities [3-5].

Researchers have studied for decades to understand the complexity of saline water intrusion and to find out possible solutions for its prediction and prevention. Commencing from theoretical analyses [6-8], laboratory studies $[1,9,10]$ and field-based investigations [11-13], the subject has undergone significant advancements. Although the alteration in the engineering properties of aquifer materials due to saltwater intrusion affects the coastal groundwater management and modelling significantly, the investigations to cover this study area have been rather limited [14]. 
The adverse effects of saline water intrusion and submarine groundwater discharge on coastal groundwater management can be prevented only when the subsurface flowpatterns of saltwater and freshwater are reasonably estimated. This requires adequate quantification of geotechnical and geohydraulic properties of aquifer material. Although significant studies have been conducted worldwide on areas related to coastal groundwater management, there exists limitations and research gap from the viewpoint of alteration in aquifer material properties in sustained contact with saltwater. The current experimental investigation has attempted to bridge up this knowledge gap.

The work reported herein is aimed towards carrying out an extensive laboratorybased study to understand the influence of saline water intrusion into the geotechnical and geohydraulic properties of sand. The test results are analyzed and interpreted, and the specific conclusions are drawn.

\section{Literature Review}

Basack et al. [15] carried out a laboratory model study with relevant mathematical analysis, followed by a field investigation to investigate the characteristics and flow pattern of saline water intrusion into a natural porous medium followed by subsequent freshwater recharge. The model tests were conducted in a rectangular flume with associate chambers for saltwater, freshwater and permeable medium. The mathematical analysis included Forchheimer flow characterizations, while the field-based study was done at a coastal region of the Indian east coast.

Fatahi et al. [1] conducted laboratory investigations on the effects of salinity and sand content on liquid limit and hydraulic conductivity. Kaolinite and bentonite clay samples were tested in the laboratory with varying sand content and saline water. Both the Atterberg limits and the hydraulic conductivity of clay were found to be affected by increasing sand content and saltwater exposure.

Tosin et al. [16] conducted a laboratory-based study on the degradation of biodegradable plastics exposed to sea water. The physio-chemical properties of such deteriorations were measured by means of three distinct test procedures: saltwater aquarium, reactor with sandy sediment and two-phase marine medium testing. It was observed that the degradation quantum depends on the specific marine environment and testing technique.

Ajalloeian et al. [17] conducted laboratory investigations to study the alteration in geotechnical properties of fine-grained soil. As observed, the Atterberg limits, compaction, consolidation, and shear strength have been significantly affected by saltwater exposure. Similar studies were conducted by other investigators [18-20].

Elmashad \& Ata [21] conducted experimental investigation on the influence of seawater on the consistency, infiltration rate, and swelling characteristics of montmorillonite clay. Studies were conducted by mixing in-situ clay with natural seawater at different concentrations. The studied indicated that an increase in salt concentration may result in a major decrease in the liquid limit, swelling characteristics, and infiltration rate of clay soils.

Although the alteration in the engineering properties of aquifer materials due to saltwater intrusion affects the coastal groundwater management and modelling significantly, the investigations to cover this study area have been rather limited [14].

Li et al. [22] conducted laboratory investigations followed by numerical simulations on the influence of subsurface barriers on saltwater intrusion. Tests were done using sandbox as a physical model and subsequent numerical models were done using FEFLOW.

Guo et al. [23] conducted experimental and numerical simulations of saltwater intrusion influenced by tidal fluctuation and groundwater withdrawal in multi-layered coastal aquifers. The laboratory model studies were conducted via a rectangular flume with three distinct chambers that were separated by filter plates with holes; the chamber consisted of a saltwater sample, porous media, and freshwater sample. The two-dimensional numerical model, on the other hand, considered density stratified flow characteristics. The study revealed the importance of inland recharge on seawater intrusion patterns. 
Etsias et al. [24] conducted a laboratory-based investigation to visualize the saline water intrusion characteristics through homogeneous and heterogeneous aquifers. The saltwater solution of a specified concentration was allowed to pass through an artificial porous medium consisting of glass beads and the flow characteristics were studied through an image processing technique via artificial neural network.

A brief review on saline water intrusion into coastal aquifers was conducted by Basack et al. [25,26]. Various theoretical analyses, laboratory model studies, field-based investigations and design recommendations carried out in the last few decades have been summarized by the authors. The analysis associated risk and appropriate research directives have also been presented. Similar review-based analyses were also conducted by Goswami et al. [27].

\section{Objective}

The past investigations revealed that the geotechnical and geohydraulic characteristics of aquifer materials are significantly influenced by continuous exposure to saline water in coastal environment. The saline concentration and period of submergence are the two specific parameters used to quantify such influence. However, a detailed experimental investigation that carries out an in-depth investigation of the alterations to the geohydraulic properties of an aquifer due to saline water intrusion is yet to be conducted.. This paper has attempted to bridge this knowledge gap.

\section{Methodology}

The research methodology adopted herein is conducts specific laboratory investigations on cohesionless soil to investigate the influence of sustained saltwater exposure on their geotechnical and geohydraulic properties. The saline concentration of saltwater and the time of submergence for the soil specimen were varied to carry out different sets of tests. The specific gravity, maximum and minimum dry densities, and permeability of the cohesionless soil samples were tested. More details of the experimentations are given in the following section.

\section{Experimentations}

The laboratory investigations were conducted to study the influence of saltwater submergence in the geohydraulic properties of aquifer material relevant to coastal environment. Locally available fine sand and rock salt samples were used to carry out the tests.

\subsection{Materials}

The cohesionless soil used as a specimen and the saltwater solution used for the tests have been described herein.

\subsubsection{Sand}

Yellowish river sand available in the local market were used to perform the experiments. A specimen that passed through a $75 \mu \mathrm{m}$ sieve and that was retained by a $425 \mu \mathrm{m}$ sieve was used for the tests. A conducted sieve analysis conducted indicates that the sand specimen was uniformly graded fine sand [28] with the values of the coefficients of uniformity and curvature being $C_{u}=1.63$ and $C_{c}=1.502$. The particle size distribution is presented in Figure 1. Several routine tests were performed in the laboratory to find out the specific gravity, dry densities and permeability of the sample. The appropriate values of these geotechnical properties are shown in Table 1.

The sand samples were collected from the bank of the river Brahmaputra in the city of Jorhat, Assam, India. The collection of disturbed samples was done by coring from a depth of $1 \mathrm{~m}$ below the ground surface. The sand was silicate consisting of more than $95 \%$ of heavy minerals including quartz and feldspar and traces of heavy minerals like chlorite, biotite, etc. The samples so collected were sieved in the laboratory to extract the finer portion of the raw sand to use in testing. 


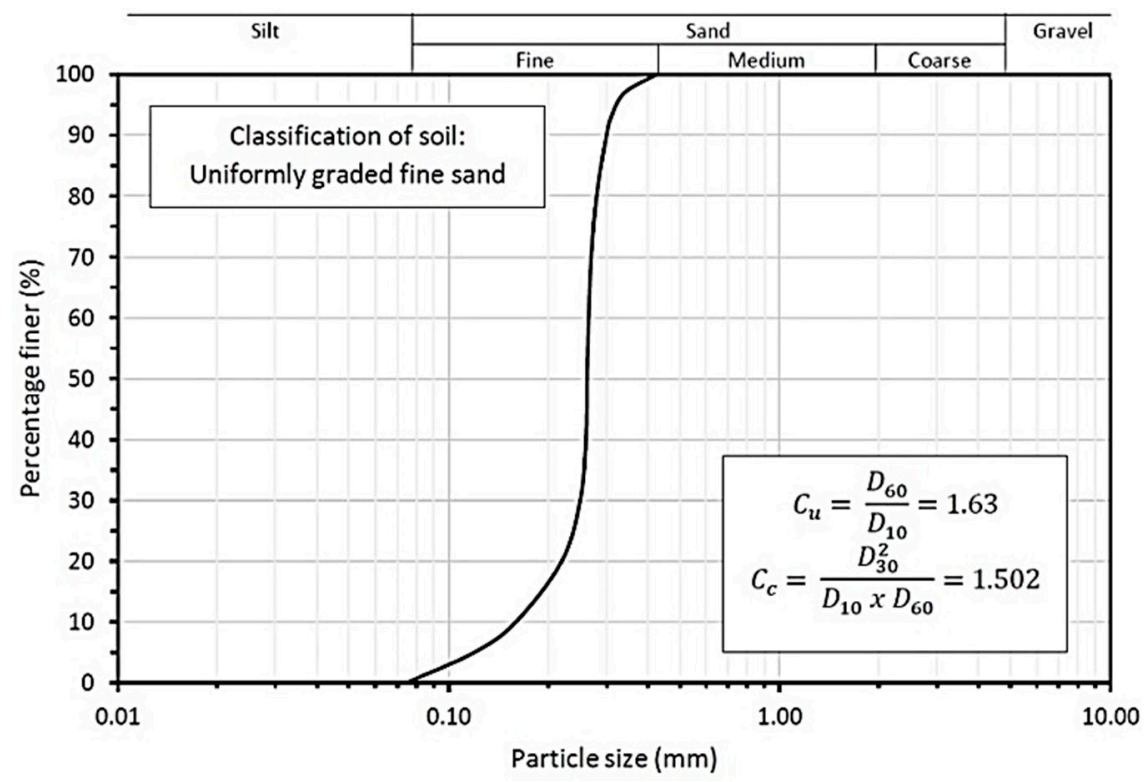

Figure 1. Particle size distribution of sand.

Table 1. Geotechnical properties of fine sand prior to saltwater submergence.

\begin{tabular}{lll}
\hline Geotechnical Properties & & Values \\
\hline \multirow{2}{*}{ Soil gradation } & Uniformity coefficient, $C_{u}$ & 1.63 \\
\cline { 2 - 3 } & Coefficient of curvature, $C_{c}$ & 1.502 \\
\hline Specific gravity of sand particles, $G$ & & 2.59 \\
\hline \multirow{2}{*}{ Dry density } & Maximum & $16.5 \mathrm{kN} / \mathrm{m}^{3}$ \\
\cline { 2 - 3 } & Minimum & $15.6 \mathrm{kN} / \mathrm{m}^{3}$ \\
\hline Coefficient of permeability ${ }^{*}, k$ & & $1.17 \times 10^{-8} \mathrm{~m} / \mathrm{s}$ \\
\hline
\end{tabular}

${ }^{*}$ All tests are conducted at a relative density of $51 \%$.

\subsubsection{Saline Water}

Locally available rock salt was dissolved in distilled water in appropriate proportion to prepare the saline water sample. The conducted chemical analysis conducted specified the predominant presence of sodium chloride ( $98 \%$ by weight), with traces of sulphates, potassium, and calcium.

The available literature suggests that the seawater in most places around the world has an average salt concentration value of 30,000-40,000 ppm; although, the saline water was classified as mild (1000-3000 ppm), moderate (3000-10,000 ppm), and high (10,000-40,000 ppm) based on its salt concentration [29-31]. Based on these ranges, the standard saline water solution was prepared by dissolving the salt in distilled water. The parameter $S$ was taken as 5000 ppm, i.e., when $5 \mathrm{gm}$ salt was dissolved in $1 \mathrm{~L}$ of distilled water [32]. This standardization was used to prepare the saline water sample of concentrations of $2 S, 4 S$, $6 \mathrm{~S}$ and $8 \mathrm{~S}$. Thus, the set of experiments covered the salinity concentration ranging from $10,000-40,000 \mathrm{ppm}$ to cover the range in consistent with the values in the coastal environments. The interval $2 S$ here is $10,000 \mathrm{ppm}$. This interval was chosen to limit the number of laboratory tests without compromising on the accuracy of the analysis and interpretation of the experimental results, especially where other variable parameters, such as period of submergence, are also involved.

\subsection{Test Procedure}

The laboratory tests were carried out by the second author of this paper under the supervision of the first and third authors herein, as an essential requirement of his postgraduate curriculum [32]. Appropriate laboratory tests were conducted to determine the 
values of the specific gravity, dry densities, and permeability of the fine sand sample prior to and after the submergence. The specific gravity of the soil particles was determined by means of pycnometric tests [33]. The maximum and minimum dry densities of the sand were found out by the vibratory table method and the rainfall technique $[34,35]$. The permeability of the soil was determined using a falling head permeameter [36]. All the permeability tests were conducted at a relative density of $51 \%$. The relative density of sand in coastal aquifers varies spatially in a wide range from loose to dense, depending upon the overburden stress. In the present study, the value has been kept in between, which is $51 \%$ for better clarity.

\subsection{Test Program}

The dry sand samples were submerged in saltwater (see Figure 2.) of specific concentrations for a specified period of submergence, as denoted in Table 2. At the end of the submergence, the samples were withdrawn from the solutions and oven dried for $24 \mathrm{~h}$ to carry out experiments.

To minimize the experimental error, each of the tests were repeated in triplicate, and the average values of the output results have been used. In the permeability tests, the same saltwater samples were used in the permeameter under which the relevant sand specimens were submerged. This ensured that the salt deposits attached to the sand particles did not leach out during the tests.

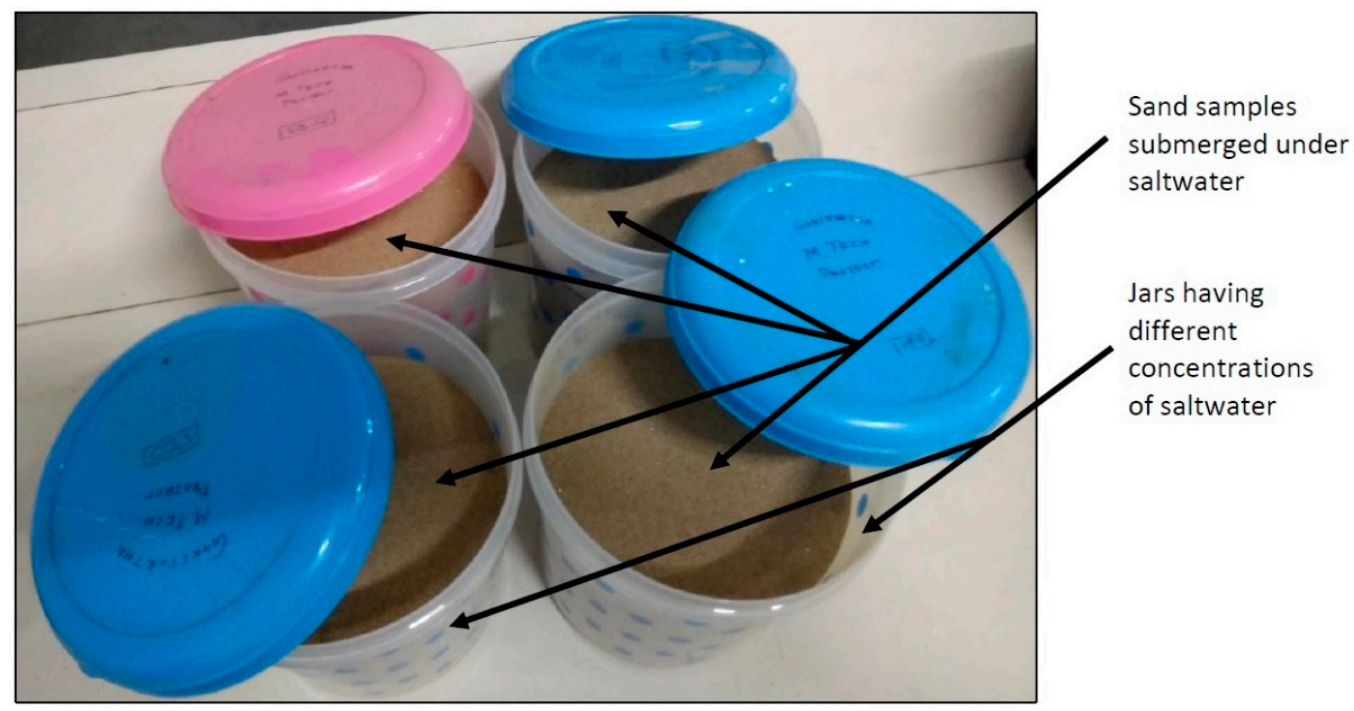

Figure 2. Sand samples submerged in saltwater of different concentrations.

Table 2. Test Matrix.

\begin{tabular}{ll}
\hline Saline Concentration $(\mathbf{S})$ & Period of Submergence (Days) \\
\hline $0.0 *$ & $0^{*}$ \\
\hline 2.0 & $1,3,7,14,21,28$ \\
\hline 4.0 & $1,3,7,14,21,28$ \\
\hline 6.0 & $1,3,7,14,21,28$ \\
\hline 8.0 & $1,3,7,14,21,28$
\end{tabular}

Note: (1) * Tests conducted with distilled water without any submergence under saltwater; (2) S = 5000 ppm; (3) All sets of tests were conducted in triplicate; (4) Total number of individual tests $=75$.

As mentioned above, all sets of tests were conducted in triplicate and the mean value has been chosen for plotting, analyses and interpretations. It is observed that for a particular set of test, the deviations between individual test results have been below $10 \%$.

In this paper, the term 'specimen' represents the materials in general that were used for testing, prior to the submergence under saltwater. The term 'sample', on the other hand, 
represents the materials which were used for specific testing after they were submerged under the saltwater. Thus, the soil specimen was submerged under saltwater of a specific concentration for a specific period of submergence and the relevant soil samples were tested for their specific gravity, dry density, and permeability.

\section{Result and Discussion}

The variation of the specific gravity, dry densities, and permeability of the sample with the period of submergence and saline concentration and the percentage increase in their values with respect to the sample prior to submergence was studied. The regression analysis has also been carried out to study the trends of the variations.

\subsection{Specific Gravity}

The variation of specific gravity of sample $G$ with the period of submergence is shown in Figure 3. With the saline concentration varying in the range of $2 S-4 S$ (i.e., $10,000-40,000 \mathrm{ppm}$ ) and the period of submergence of 1-28 days, the values of specific gravity were found to vary from 2.33 to 2.72 . The specific gravity was found to increase fairly linearly with the period of submergence. The percentage increase in the values of $G$ with respect to its value prior to submergence has been studied (see Figure 4). For the saline concentration of $2 S$ and $4 S$, a decrease in the values of $G$ was observed, as indicated by the negative value of percentage increase varying from 0 to $-9.8 \%$. For higher saline concentrations, the values of $G$ were observed to increase in the range of $0-4.5 \%$.

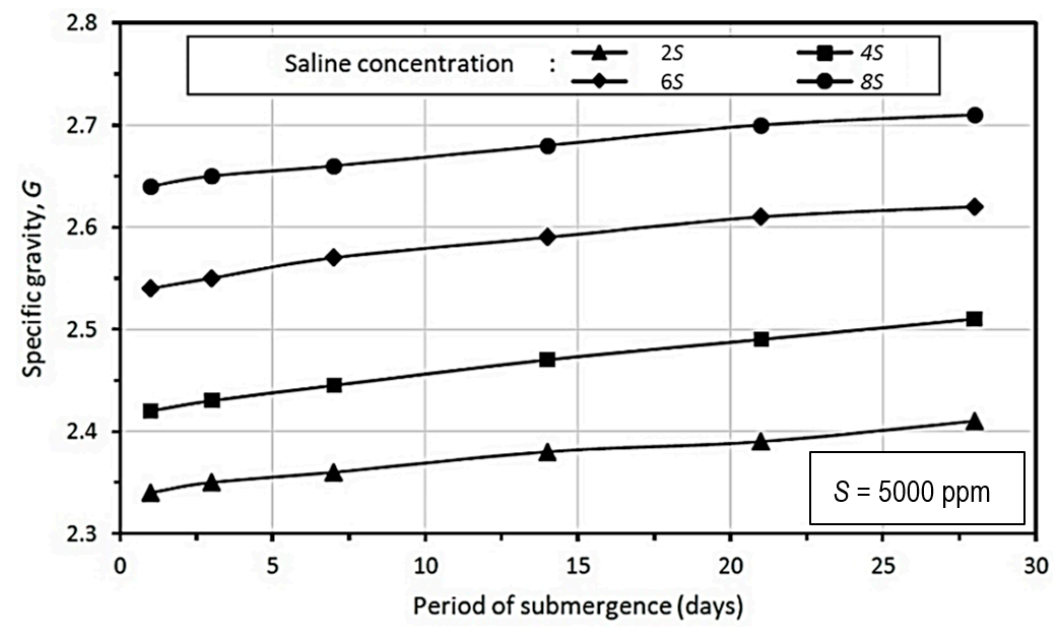

Figure 3. Variation of $G$ with period of submergence.

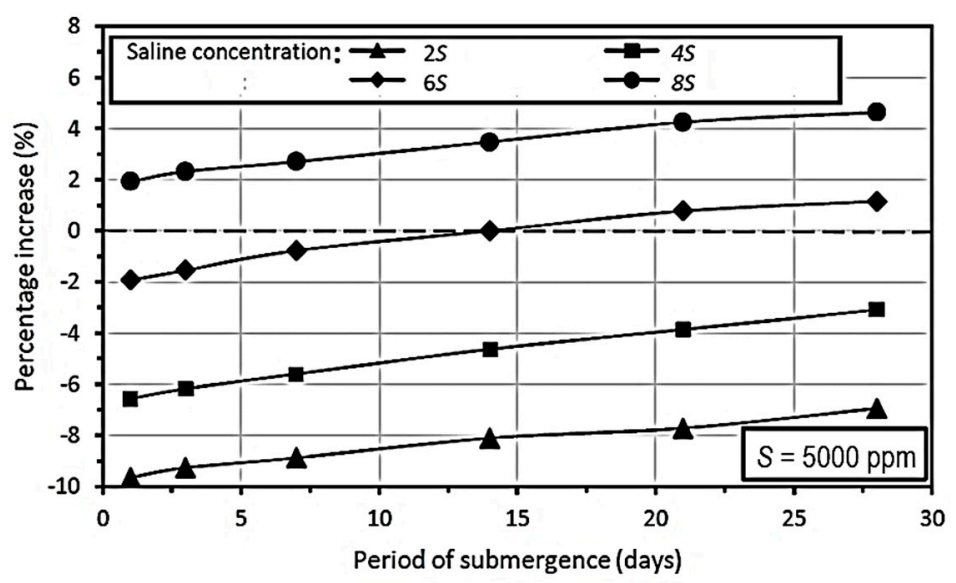

Figure 4. Variation in the percentage increase of $G$ with period of submergence.

The variation of $G$ with respect to saline concentration is portrayed in Figure 5. The values of $G$ were found to increase following a fair linear trend with ascending saline 
concentration. The percentage increase in $G$ with respect to saline concentration, as presented in Figure 6, indicated a negative value for most of the tests, until the period was submergence is attained beyond 21 days.

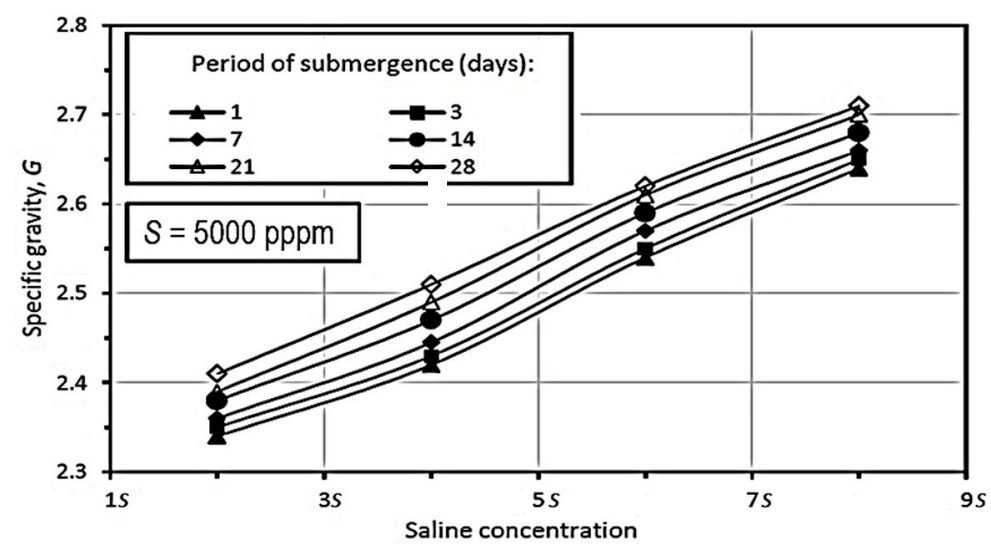

Figure 5. Variation of specific gravity with saline concentration.

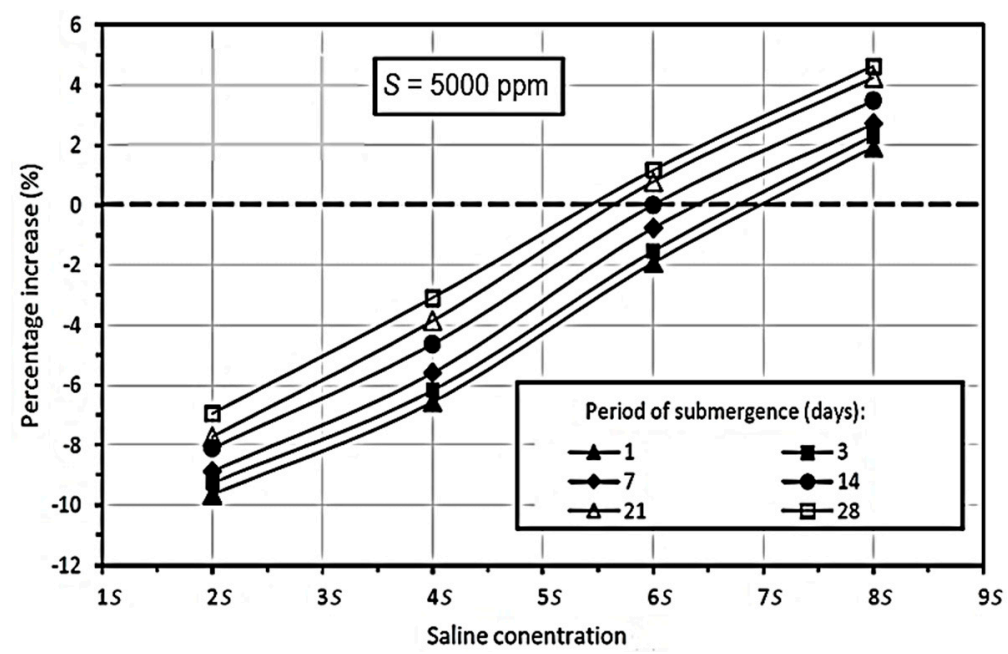

Figure 6. Variation of percentage increase in the value of $G$ with saline concentration.

The above observations are possibly due to the chemical decomposition of sand particles at lower saline concentrations and period of submergence, producing a reduction in the specific gravity. For higher values of saline concentration and period of submergence, a partial reversal might have occurred, initiating an opposite effect.

In coastal sand, the mineralogical composition includes quartz and silica as its most common minerals, but also includes feldspar, iron and manganese oxides, alunite, anhydrite, and kaolinite as other materials $[37,38]$. Sustained contact between coastal soil and saltwater initiates alteration in the specific gravity of sand particles due to dissolution of some of the major constituent minerals in saltwater involving independent removal of cations and anions from the surface of sand particles. Moreover, fluid absorption and flocculation on the sand particles could also modify its specific gravity. The influence of different mineral composition on the test results was largely dependent on the appropriate correlations relevant to the rates of dissolution of minerals and the fluid absorption, which included specific quantifications of various parameters such as chemical affinity, specific surface area, activation energy, viscosity, porosity, etc. Based on these quantifications, the effects of different sand with diverse mineralogical compositions on the current test results could be estimated [39-42]. 


\subsection{Dry Density}

Figure 7 represents the plot of dry densities against the period of submergence. The values of maximum and minimum dry densities $\gamma_{d}^{\max }$ and $\gamma_{d}^{\min }$ are varied in the ranges of 16.2-17.3 and 14.2-15.5, respectively. The values of dry densities decreased with an ascending period of submergence. The percentage increase in the values of dry densities with respect to their values prior to submergence against the period of submergence is plotted in Figure 8. A decrease in the value of $\gamma_{d}^{\min }$ in the range of 2.5-11\% occurred for the experimental ranges of the period of submergence and saline concentration. On the other hand, the value of $\gamma_{d}^{\max }$ increased only for the early period of submergence (i.e., 1-7 days).

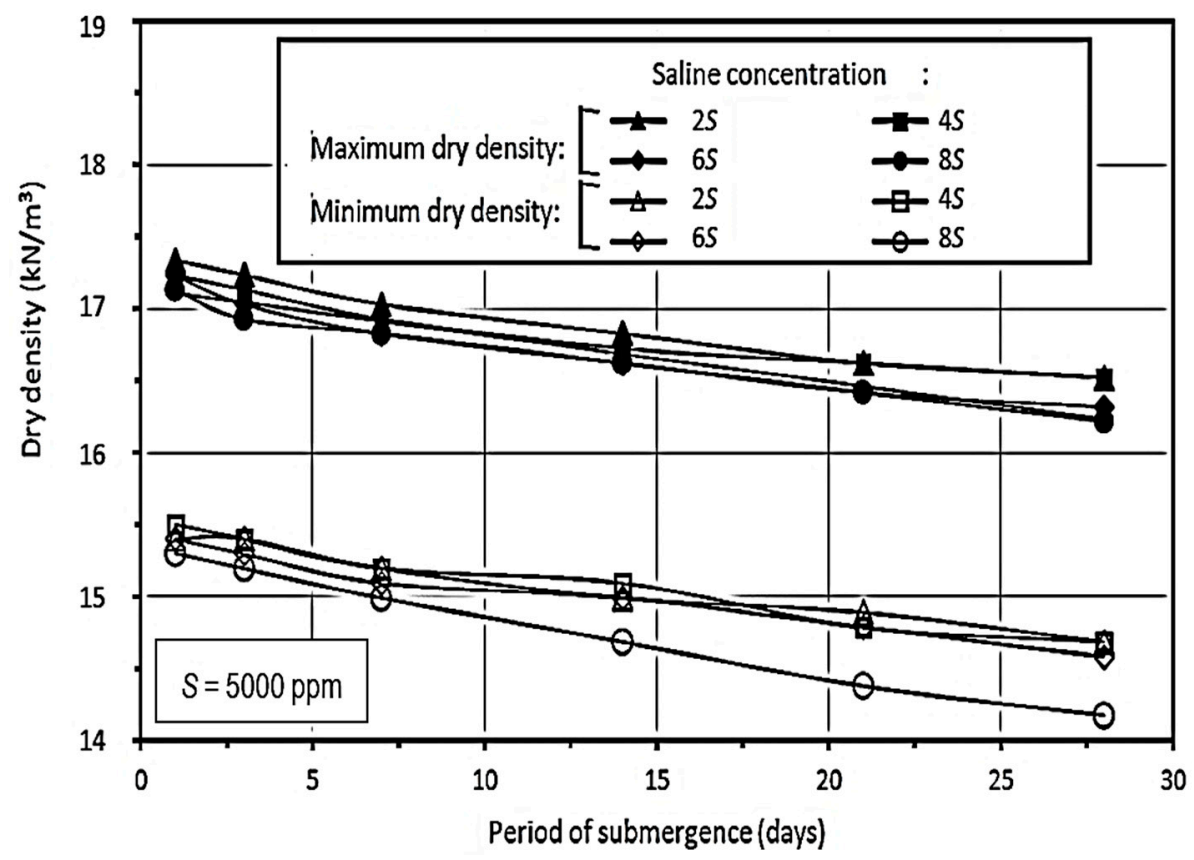

Figure 7. Variation of normalized dry density with period of submergence.

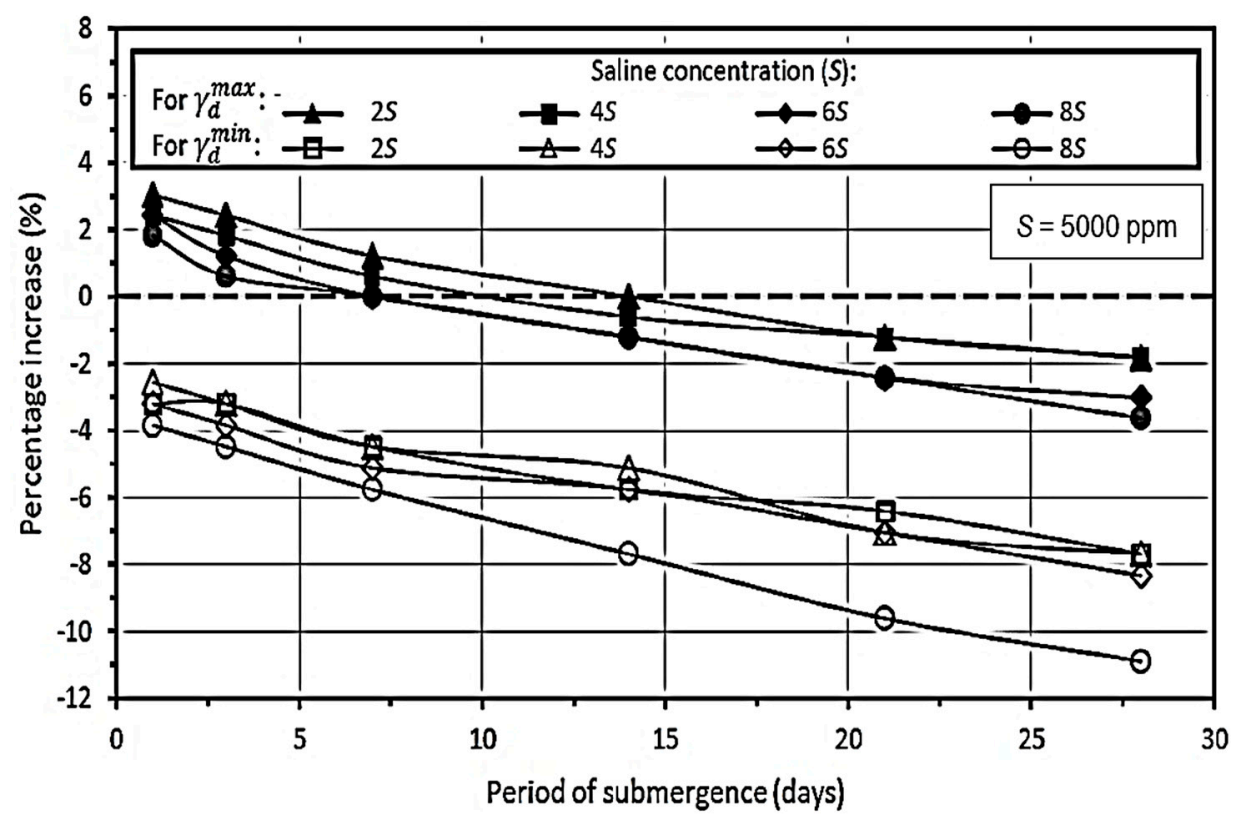

Figure 8. Variation of percentage increase in dry densities with period of submergence.

Figure 9 portrays the variation of normalized dry densities with saline concentration. As observed, the dry densities remained unaffected by the alteration in saline concentration, 
except for the higher periods of submergence ( $>21$ days). The plots of percentage increased in the dry densities versus saline concentration, shown in Figure 10, which indicated a similar trend.

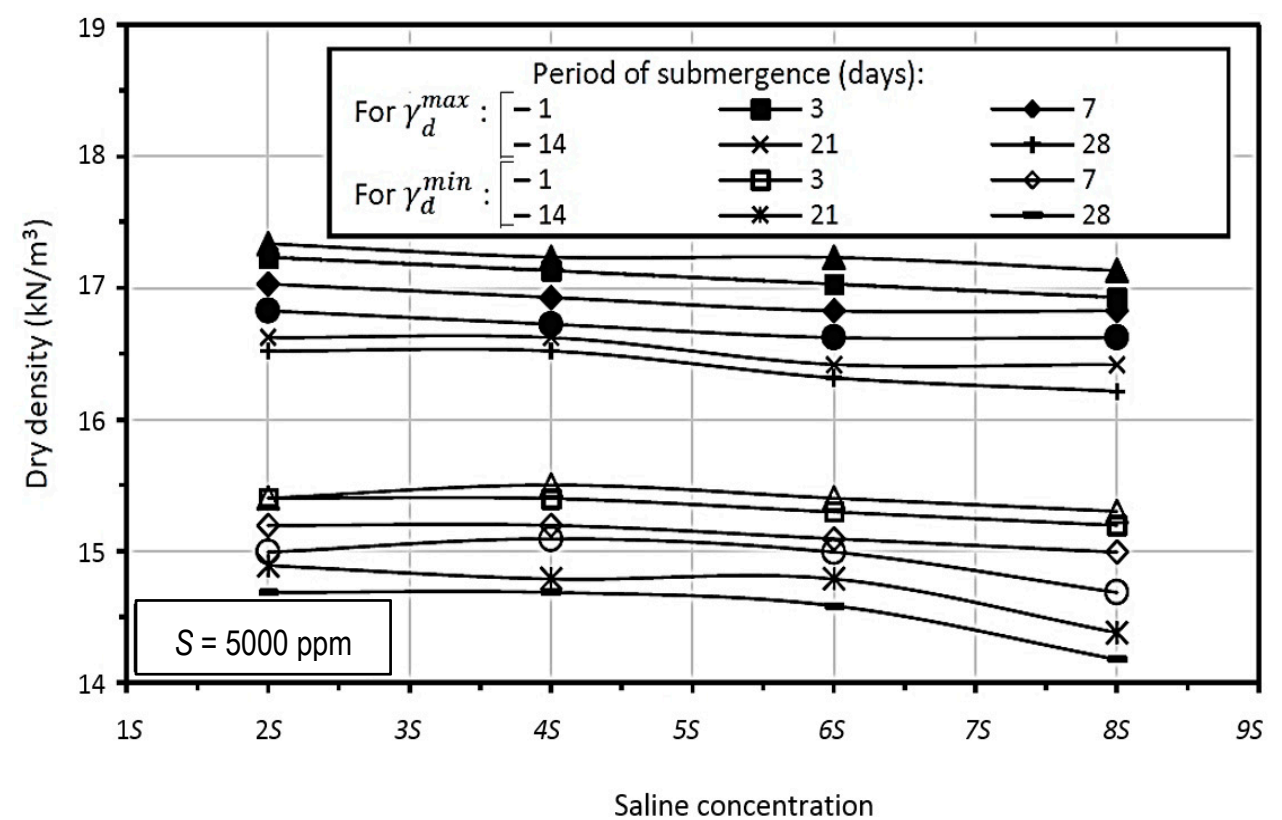

Figure 9. Variation of normalized dry density with saline concentration.

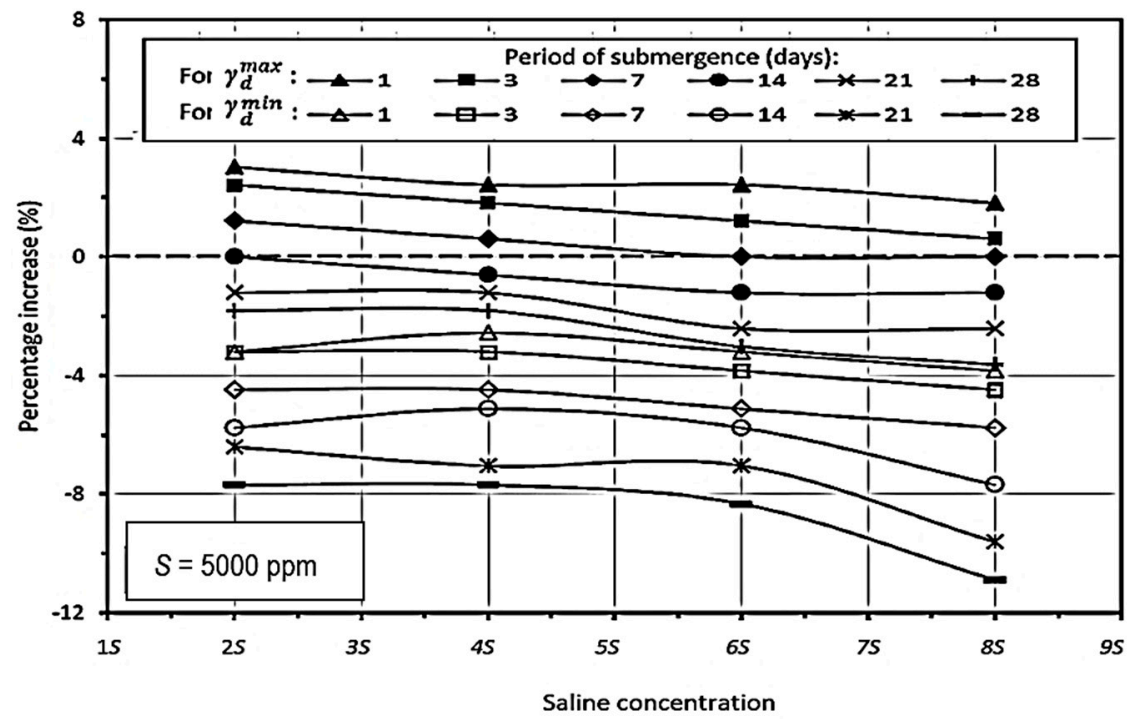

Figure 10. Variation of percentage increase in dry density with saline concentration.

The above observations may be justified by the influence of a diffused double layer on the sand particles, which were initially unsaturated in dry conditions, the thickness of which might have progressively reduced on sustained saltwater submergence $[17,43]$.

\subsection{Permeability}

The variation of the coefficient of permeability $k$ of the sand sample with the period of submergence is presented in Figure 11. The value of $k$ varied from $4.97 \times 10^{-8} \mathrm{~m} / \mathrm{s}$ to $19.51 \times 10^{-8} \mathrm{~m} / \mathrm{s}$ for the experimental ranges in the period of submergence and saline concentration. With increasing the period of submergence, the parameter $k$ increased in a curvilinear manner with a descending slope, until a peak value was attained at 14 days; the values of $k$ decreased beyond such peak points. The peak value of $k$ varied between $8.1 \times 10^{-8} \mathrm{~m} / \mathrm{s}$ and $19.51 \times 10^{-8} \mathrm{~m} / \mathrm{s}$. The plot of percentage increase in the parameter $\mathrm{k}$ 
with the period of submergence, shown in Figure 12, revealed a similar pattern, with the percentage increase with respect to the value prior to submergence varying from $4100 \%$ to $16,400 \%$. Thus, the permeability attained a maximum value for a submergence period of 14 days and salinity concentration of $6 S$, and slope of the relevant curve is also quite steep.

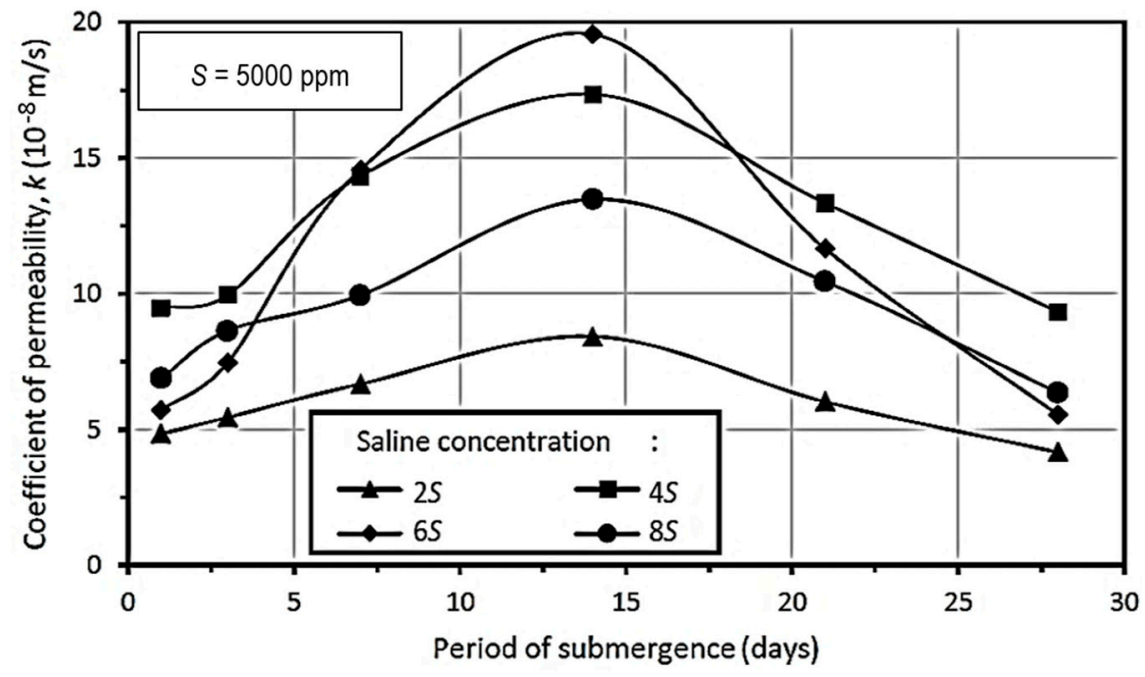

Figure 11. Variation of $k$ with period of submergence.

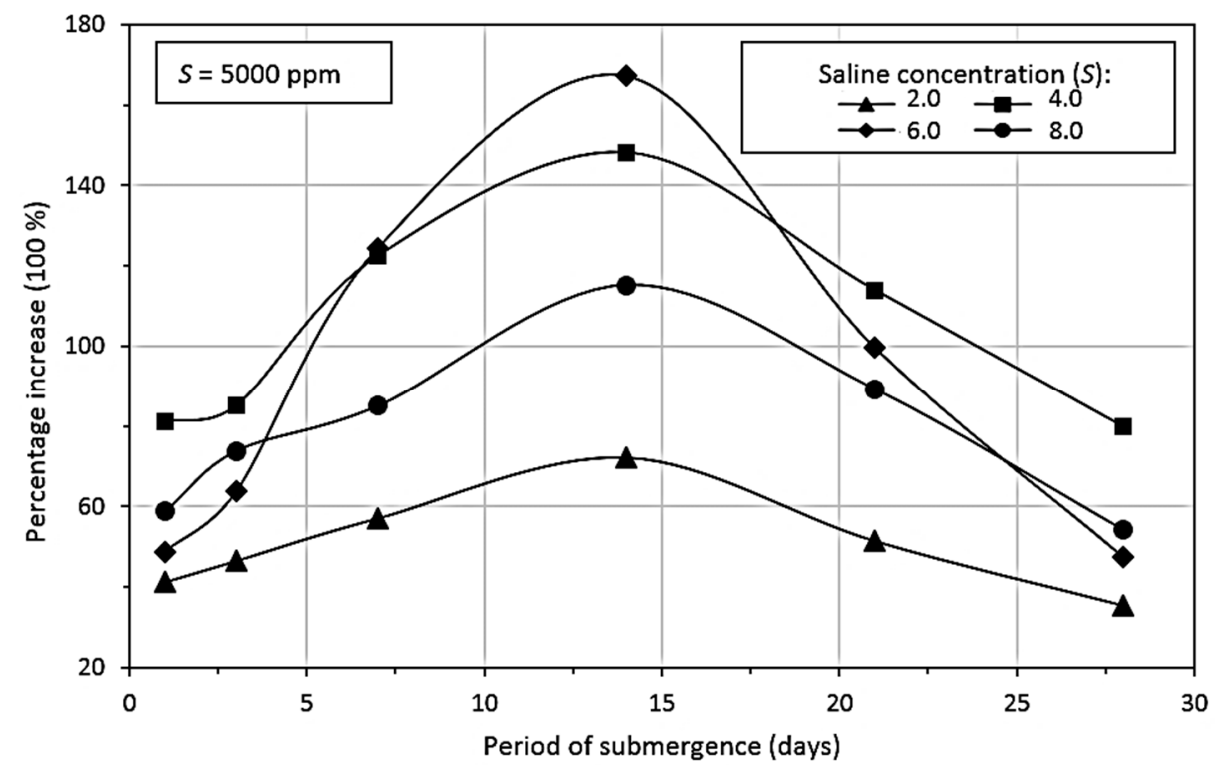

Figure 12. Variation of percentage increase in permeability with period of submergence.

The variation of $k$ with saline concentration is depicted in Figure 13. As observed, the pattern of variation is curvilinear. Initially the $k$ increased with ascending saline concentration with a descending slope, until a point of inflection was attained; the curves thereafter assumed opposite trends. The point of inflection was found to occurred at a saline concentration of $6 S$, except for the periods of submergence of 14 days and 21 days where inflection took place beyond the saline concentration of $8 S$. The peak values of $k$ occurred at saline concentrations of 4.13S, $5.2 \mathrm{~S}$ and $5.9 \mathrm{~S}$ for the periods of submergence of 21 days, 7 days, and 14 days respectively; for the remaining period of submergence, however, the peak value attained at a saline concentration of $4 S$. The plot of percentage increase in the parameter $k$ with the saline concentration, shown in Figure 14, revealed a similar pattern. 


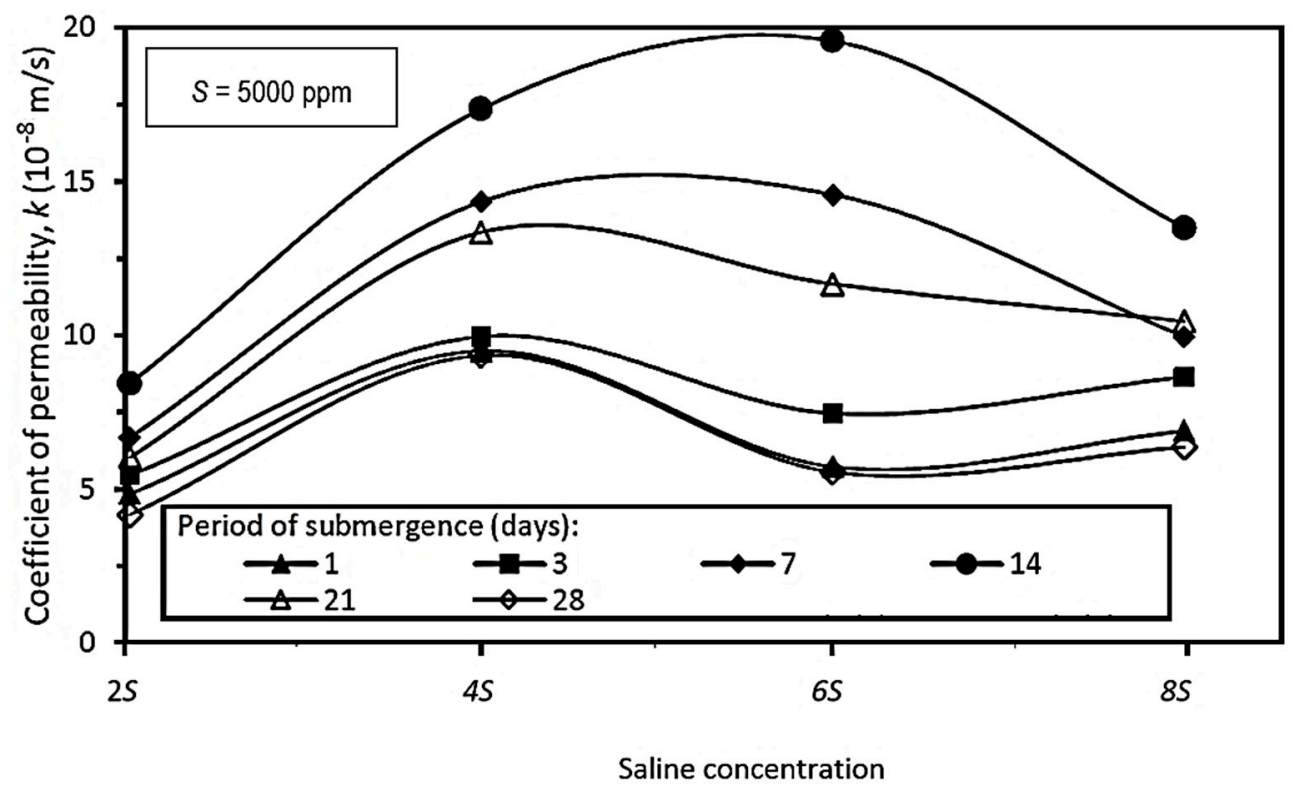

Figure 13. Variation of $k$ with saline concentration.

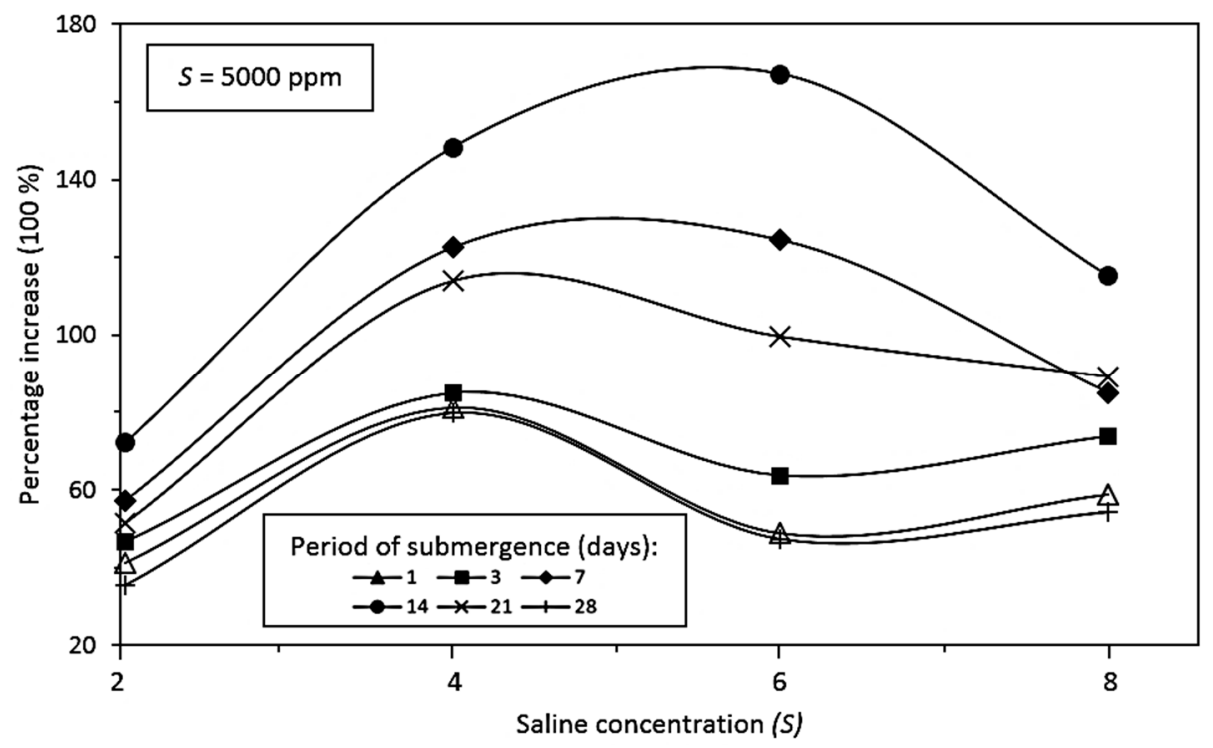

Figure 14. Variation of percentage increase in permeability with saline concentration.

The possible reason for this pattern of variation is the complex chemical and electrochemical interaction between the sand particles and the saline solution including cation exchange and anion adsorption, apart from the effects of fluid concentration and stress on the diffused double layer [44].

As stated in Section 2, the limited literature available on the study area focused on the alteration of geotechnical properties with saltwater submergence in case of soft cohesive soil. Since the current study emphasizes about sand, direct comparison of the current experimental results with existing results is unfeasible. However, a simplified comparison of the variation of permeability of soil with period of submergence between the current experimental results and those obtained for kaolin clay in a previous study [1] have been presented in Figure 15. For comparison, the value of soil permeability was normalized by its relevant value prior to submergence. As observed, the pattern of variation of the two different types of soil have been different. 


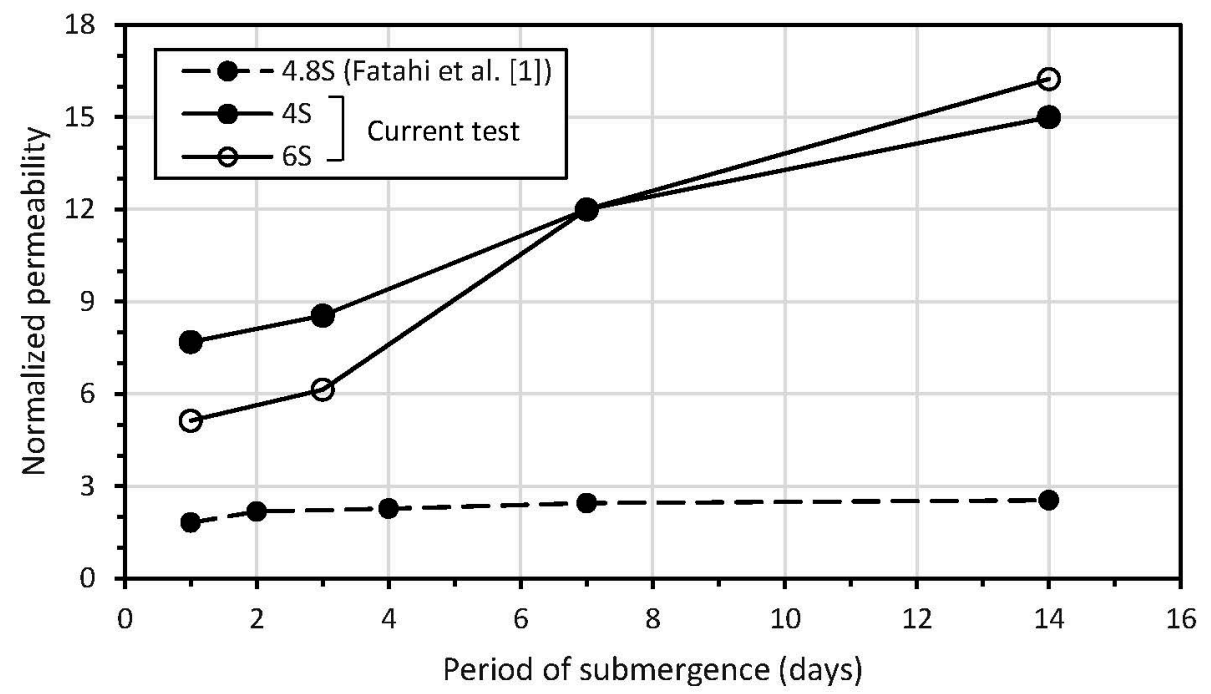

Figure 15. Comparison with existing literature.

\subsection{Influence of Particle Size}

In the case of coastal aquifers, the material may be fine sand, although they might as well be medium or coarse sand and even pebbles [45-47]. The current experimental program was conducted by choosing fine sand as the test material. However, in the cases of medium or coarse sand, the test results are likely to be different.

\section{Conclusions}

The influence of saltwater intrusion on the geotechnical and geohydraulic properties of fine sand has been studied through laboratory investigation. The conclusions drawn are presented herein.

It is worth mentioning here that in the cases of medium or coarse sand, the test results are likely to be different. Alteration in particle size distribution and gradation initiates variation in certain parameters including specific surface, porosity, permeability, etc. This is likely to influence the interaction potential between the saltwater and soil particles affecting dissolution, fluid absorption and flocculation, as described earlier. Such influence in turn is likely to affect the experimental results. The authors are currently investigating this important study aspect and interesting results are expected to be derived for future publications.

The study reveals that the geohydraulic properties of sand varied with the period of submergence and saline concentration of salt water. The period of submergence varied in the range of 1-28 days, while the saline concentration varied from $2 S$ to $8 S$, where, $S=5000 \mathrm{ppm}$.

The specific gravity $G$ of sand particles increases following a linear pattern with an ascending period of submergence and saline concentration. With respect to the of value of $G$ relevant to prior submergence, the parameter was initially found to decrease in magnitude for lower saline concentration and a lesser period of submergence. On the contrary, the value of $G$ was found to increase for higher saline concentrations and periods of submergence. The increase in magnitude of $G$ varied in the range of $-9.8 \%$ to $4.5 \%$.

Dissolution of few minerals in saltwater with ion removal from the particle surface, together with fluid absorption and flocculation on sand particles have possibly altered the specific gravity.

The maximum and minimum dry densities of the sand decreased with an ascending period of submergence but remained unaffected with the alteration in saline concentration. In comparison with the values prior to submergence, the dry densities decreased due to saltwater intrusion, except for the maximum dry density at initial period of submergence. The possible gradual reduction of the diffused double layer thickness on the sand particles influenced the observed variation in dry densities of sand. The increase in the magnitudes 
of maximum and minimum dry densities of sand were observed to vary in the ranges of $-3.8 \%$ to $3 \%$ and $-11 \%$ to $-2.5 \%$, respectively.

With increasing period of submergence, the parameter $k$ increased curvilinearly with a descending slope, until a peak value was attained, and decreased thereafter. On the other hand, $k$ increased with ascending saline concentration with a descending slope, until a point of inflection was attained; the curves thereafter assumed opposite trends. The percentage increase in the values of $k$ compared to the value prior to submergence was $40-160 \%$. The observed pattern of variation has been justified by the probable chemical and electrochemical interaction between the sand particles and the saline solution including ion exchange and adsorption, aside from fluid concentration and stress on the diffused double layer. Increase in the magnitude of sand permeability varied from $4100 \%$ to $16,400 \%$. The permeability attained a maximum value for a submergence period of 14 days and saline concentration of 30,000 ppm, the slope of the relevant curve being quite steep.

From the spatial variation of coastal salinity, it is possible to reasonably estimate the salt concentration and period of submergence of aquifer material in a specific coastal zone [48]. The variation in geotechnical properties of the aquifer materials due to saline water intrusion can be further estimated using the current laboratory test results, which can be applied to model the coastal groundwater flow and design of appropriate remedial measures against such intrusion.

Author Contributions: Conceptualization, S.B.; Methodology, S.B.; Investigation, S.B. and G.G.; Data Curation, S.B. and G.G.; Formal Analysis, S.B., G.G. and M.K.; Writing-Original Draft Preparation, S.B.; Writing-Review \& Editing, S.B., G.G. and M.K.; Visualization, S.B. and M.K.; Supervision, S.B. and S.S.; Project Administration, S.B. and S.S. All authors have read and agreed to the published version of the manuscript.

Funding: This research receives no external funding.

Data Availability Statement: Data will be made available from corresponding author on reasonable request.

Acknowledgments: The authors thankfully acknowledge the assistance received from Rupantor Senapati, Technical Assistant, Geotechnical Engineering Laboratory, during the experimentation.

Conflicts of Interest: The authors declare that there is no conflict of interest in this paper.

\section{Nomenclature}

The following notations are used in this paper:

$C_{c} \quad$ Coefficient of curvature.

$C_{u} \quad$ Uniformity coefficient.

$G \quad$ Specific gravity of solid particles.

$k \quad$ Coefficient of permeability.

$S \quad$ Saline concentration.

$\gamma_{d}^{\max }, \gamma_{d}^{\min }$ Maximum and minimum unit weights of soil.

$\gamma_{w} \quad$ Unit weight of water.

\section{References}

1. Fatahi, B.; Khabbaz, H.; Basack, S. Effects of salinity and sand content on liquid limit and hydraulic conductivity. Aust. Geomech. 2011, 46, 67-76.

2. Todd, D.K. Salt water intrusion of coastal aquifers in the United States. Subterr. Water 1960, 52, $452-461$.

3. Reilly, T.E.; Goodman, A.S. Analysis of saltwater upconing beneath a pumping well. J. Hydrol. 1987, 89, 169-204. [CrossRef]

4. Bhattacharya, A.K.; Basack, S.; Maity, P. Groundwater extraction in the United Arab Emirates under the constraint of saline water intrusion. J. Environ. Hydrol. 2004, 12, 6. Available online: www.hydroweb.com/journal-hydrology-2004-paper-6.htm (accessed on 5 September 2021).

5. Basack, S.; Bhattacharya, A.K.; Maity, P. A coastal groundwater management model with Indian case study. Water Manag. 2014, 167, 126-140. [CrossRef]

6. Bobba, A.G. Mathematical models for saltwater intrusion in coastal aquifers. Water Res. Manag. 1992, 7, 3-37. [CrossRef]

7. Haitjema, H.; Kuzin, S.; Kelson, V.; Abrams, D. Modelling flow into horizontal wells in a Dupuit-Forchheimer model. Groundwater 2010, 48, 878-883. [CrossRef] [PubMed] 
8. Cai, J.; Taute, T.; Schneider, M. Saltwater upcoming below a pumping well in an inland aquifer: A theoretical modelling study on testing different scenarios of deep saline-groundwater pathways. Water Air Soil Pollut. 2014, 225, 221-232. [CrossRef]

9. Park, S.U.; Kim, J.M.; Yum, B.W.; Yeh, G.T. Three-dimensional numerical simulation of saltwater extraction schemes to mitigate seawater intrusion due to groundwater pumping in a coastal aquifer system. J. Hydrol. Eng. 2012, 17, 10-22. [CrossRef]

10. Mehdizadeh, S.S.; Vafaie, F.; Abolghasemi, H. Assessment of sharp-interface approach for saltwater intrusion prediction in an unconfined coastal aquifer exposed to pumping. Environ. Earth Sci. 2015, 73, 8345-8355. [CrossRef]

11. Bhattacharya, A.K.; Basack, S.; Maity, P. Groundwater Quality Modelling and Management of Saline Water Intrusion with Special Emphasis on Purba Medinipur District, West Bengal, India; River Research Institute: Faridpur, Bangladesh, 2010; pp. 39-53.

12. Lathashri, U.A.; Mahesha, A. Predictive simulation of seawater intrusion in a tropical coastal aquifer. J. Environ. Eng. 2016, 142, 123-131. [CrossRef]

13. Prasad, K.V.S.R.; Sridevi, T.; Sadhuram, Y. Influence of dam-controlled river discharge and tides on salinity intrusion in the Godavari estuary, east coast of India. J. Waterw. Port Coast. Ocean. Eng. 2018, 144, 562-571. [CrossRef]

14. Abu Zeid, M.M.; El-Aal, A.K.A. Effect of salinity of groundwater on the geotechnical properties of some Egyptian clay. Egyp. J. Pet. 2017, 26, 643-648. [CrossRef]

15. Basack, S.; Bhattacharya, A.K.; Sahana, C.; Maity, P. A study on saline water intrusion and freshwater recharge relevant to coastal environment. WSEAS Trans. Fluid Mech. 2010, 5, 80-90.

16. Tosin, M.; Weber, M.; Siotto, M.; Lott, C.; Innocenti, F.D. Laboratory test methods to determine the degradation of plastics in marine environmental conditions. Front. Microbiol. 2012. [CrossRef] [PubMed]

17. Ajalloeian, R.; Mansouri, H.; Sadeghpour, A.M. Effect of saline wwater on geotechnical properties of fine grained soil. Electron. J. Geotech. Eng. 2013, 18, 1419-1435.

18. Pathak, Y.; Pathak, A. Effect of saline water on geotechnical properties of soil. Int. J. Innov. Res. Sci. Eng. Technol. 2016, 5, 16181-16187.

19. Arora AP, S.; Das, K.; Sengupta, D.; Maity, J. Effect of sea water on the geotechnical properties of cohesive soil. Int. Res. J. Eng. Technol. 2018, 5, 3003-3006.

20. Al-Obaidi, A.; Ihssan, A.; Allawi, H. Studying of the combined salts effect on the engineering properties of clayey soil. Proc. MATEC Web Conf. 2018, 162, 01011. [CrossRef]

21. Elmashad, M.E.; Ata, A.A. Effect of seawater on consistency, infiltration rate and swelling characteristics of montmorillonite clay. HBRC J. 2016, 12, 175-180. [CrossRef]

22. Li, F.L.; Chen, X.Q.; Liu, C.H.; Lian, Y.Q.; He, L. Laboratory tests and numerical simulations on the impact of subsurface barriers to saltwater intrusion. Nat. Hazards 2018, 91, 1223-1235. [CrossRef]

23. Guo, Q.; Huang, J.; Zhou, Z.; Wang, J. Experiment and numerical simulation of seawater intrusion under the influences of tidal fluctuation and groundwater exploitation in coastal multilayered aquifers. Geofluids 2019, 2019, 2316271. [CrossRef]

24. Etsias, G.; Hamill, G.A.; Benner, E.M.; Aguila, J.F.; McDonell, M.C.; Flynn, R.; Ahmed, A.A. Optimizing laboratory investigations of saline intrusion by incorporating machine learning techniques. Water 2020, 12, 2996. [CrossRef]

25. Basack, S.; Loganathan, M.K.; Goswami, G.; Khabbaz, H. Saltwater intrusion into coastal aquifers and associated risk management: Critical review and research directives. J. Coast. Res. 2022. In Press.

26. Basack, S.; Loganathan, M.K.; Goswami, G.; Baruah, P.; Alam, R. Review of risk assessment and mitigation measures of coastal aquifers vulnerable to saline water intrusion. Pol. J. Environ. Stud. 2022, 31, 2, in press. [CrossRef]

27. Goswami, G.; Basack, S.; Mastorakis, N.; Saikia, A.; Nilo, B.; Ahmed, N. Coastal ground water flow and management: A state-of-the-art review. Int. J. Mech. 2020, 14, 37-48. [CrossRef]

28. USDA. Soil Mechanics Level 1, Module 3: USDA Textural Classification Study Guide; National Employee Development Staff, Soil Conservation Service, U.S. Department of Agriculture: Washington, DC, USA, 1987.

29. Swenson, H.A.; Baldwin, H.L. A Primer on Water Quality; USGS Series; GIP: Reston, VA, USA, 1965. Available online: https:/ / www.usgs.gov / special-topic/water-science-school/science/saline-waterand-salinity?qt-science_center_objects=0\#qtscience_center_objects (accessed on 5 September 2021).

30. Shogaki, T. Mechanism of sample disturbance caused by tube penetration: Model tests on Toyoura sand. Soils Found. 2017, 57, 527-542. [CrossRef]

31. Nthunya, L.N.; Maifadi, S.; Mamba, B.B.; Verliefde, A.R.; Mhlanga, S.D. Spectroscopic determination of water salinity in brackish surface water in Nandoni Dam, at Vhembe District, Limpopo Province, South Africa. Water 2018, 10, 990. [CrossRef]

32. Goswami, G. A Laboratory Study on the Influence of Saltwater Intrusion on Sand Relevant to Coastal Environment. Master's Thesis, Department of Civil Engineering, Kaziranga University, Jorhat, India, 2019.

33. ASTM. Standard Test Methods for Specific Gravity of Soil Solids by Water Pycnometer; D854-00; ASTM International: West Conshohocken, PA, USA, 2000. Available online: www.astm.org (accessed on 7 June 2020).

34. ASTM. Evaluation of Relative Density and Its Role in Geotechnical Projects Involving Cohesionless Soils; STP 523; ASTM: West Conshohocken, PA, USA, 1973. Available online: www.astm.org (accessed on 7 June 2020).

35. Lunne, T.; Knudsen, S.; Blaker, T.; Vestgarden, J.J.M.; Powell CFWallace, L.; Krogh, N.V.; Thomsen, G.; Yetginer, R.K.; Ghanekar, R.K. Methods used to determine maximum and minimum dry unit weights of sand: Is there a need for a new standard? Can. Geotech. J. 2019, 56, 536-553. [CrossRef] 
36. ASTM. Standard Test Methods for Measurement of Hydraulic Conductivity of Saturated Porous Materials Using a Flexible Wall Permeameter; D5084-03; ASTM International: West Conshohocken, PA, USA, 2003. Available online: www.astm.org (accessed on 7 June 2020).

37. Crundwell, F.K. On the mechanism of the dissolution of quartz and silica in aqueous solutions. ACS Omega 2017, 2, 1116-1127. [CrossRef]

38. Tzifas, I.T.; Misaelides, P.; Godelitsas, A.; Gamaletsos, P.N.; Nomikou, P.; Karydas, A.G.; Kantarelou, V.; Papadopolous, A. Geochemistry of coastal sands of Eastern Mediterranean: The case of Nisyros volcanic materials. Geochemistry 2017, 77, 487-501. [CrossRef]

39. Hall, C.; Marchand, J.; Gerard, G.; Sosoro, M. Transport of fluids in homogenous isotropic cementitious composites. In Penetration and Permeability of Concrete; Reinhardt, H.W., Ed.; RILEM Report; Springer: Berlin/Heidelberg, Germany, 1997; Volume 16, pp. $5-79$.

40. Nangia, S.; Garrison, B.J. Reaction rates and dissolution mechanisms of quartz as a function of pH. J. Phys. Chem. A 2008, 112, 2027-2033. [CrossRef]

41. Farnam, Y.; Washington, T.; Weiss, J. The influence of calcium chloride salt solution on the transport properties of cementitious materials. Adv. Civ. Eng. 2015, 2015, 929864. [CrossRef]

42. Basack, S.; Goswami, G.; Nimbalkar, S. Analytical and Numerical Solutions to Selected Research Problems in Geomecanics and Geohydraulics. WSEAS Trans. Appl. Theor. Mech. 2021, 16, 222-231. [CrossRef]

43. Schmitz, R.M. Can the diffuse double layer theory describe changes in hydraulic conductivity of compacted clays? Geotech. Geol. Eng. 2006, 24, 1835-1844. [CrossRef]

44. Sivapullaiah, P.V. Effects of soil pollution on geotechnical behaviour of soils. In Proceedings of the Indian Geotechnical Conference, Guntur, India, 17-19 December 2009; pp. 933-940.

45. Merli, A.; Capatti, M.C.; Dezi, F. Different measuring methods for estimating the hydraulic conductivity on the shallow aquifer along a stretch of the Rimini coast. Procedia Eng. 2016, 158, 434-439. [CrossRef]

46. Lee, W.D.; Yoo, Y.J.; Jeong, Y.M.; Hoor, D.S. Experimental and numerical analysis on hydraulic characteristics of coastal aquifers with seawall. Water 2019, 11, 2343. [CrossRef]

47. Woodruff, D.; Venti, N.L.; Mabee, S.B.; DiToria, A.L.; Beach, D. Grain size and beach face slope on paraglacial beaches of New England, USA. Mar. Geol. 2021, 438, 106527. [CrossRef]

48. Wang, Z.; Zhao, G.; Gao, M.; Chang, C. Spatial variability of soil salinity in coastal saline soil at different scales in the Yellow River Delta, China. Environ. Monit. Assess. 2017, 189, 80. [CrossRef] 